Review

\title{
Survey of Molecular Mechanisms of Hyperbaric Oxygen in Tissue Repair
}

\author{
Joerg Lindenmann ${ }^{1, *}++^{(D)}$, Christian Smolle ${ }^{2,+}\left(\mathbb{D}\right.$, Lars-Peter Kamolz ${ }^{2}$, Freyja Maria Smolle-Juettner ${ }^{1}$ \\ and Wolfgang F. Graier ${ }^{3}$ (D)
}

check for updates

Citation: Lindenmann, J.; Smolle, C.; Kamolz, L.-P.; Smolle-Juettner, F.M.; Graier, W.F. Survey of Molecular Mechanisms of Hyperbaric Oxygen in Tissue Repair. Int. J. Mol. Sci. 2021, 22, 11754. https://doi.org/10.3390/ ijms222111754

Academic Editor: Arcangelo Liso

Received: 30 September 2021

Accepted: 26 October 2021

Published: 29 October 202

Publisher's Note: MDPI stays neutral with regard to jurisdictional claims in published maps and institutional affiliations.

Copyright: (c) 2021 by the authors. Licensee MDPI, Basel, Switzerland. This article is an open access article distributed under the terms and conditions of the Creative Commons Attribution (CC BY) license (https:// creativecommons.org/licenses/by/ $4.0 /)$
1 Division of Thoracic and Hyperbaric Surgery, Department of Surgery, Medical University of Graz, Auenbruggerplatz 29/3, 8036 Graz, Austria; freyja.smolle@medunigraz.at

2 Division of Plastic, Aesthetic and Reconstructive Surgery, Department of Surgery, Medical University of Graz, Auenbruggerplatz 29/2, 8036 Graz, Austria; christian.smolle@medunigraz.at (C.S.); lars.kamolz@medunigraz.at (L.-P.K.)

3 Gottfried Schatz Research Center for Cell Signaling, Metabolism and Aging Molecular Biology and Biochemistry, Medical University of Graz, Neue Stiftingtalstraße 6/6, 8010 Graz, Austria; wolfgang.graier@medunigraz.at

* Correspondence: jo.lindenmann@medunigraz.at

+ Joerg Lindenmann and Christian Smolle contributed equally as first authors to this paper.

\begin{abstract}
For more than six decades, hyperbaric oxygen (HBO) has been used for a variety of indications involving tissue repair. These indications comprise a wide range of diseases ranging from intoxications to ischemia-reperfusion injury, crush syndrome, central nervous injury, radiationinduced tissue damage, burn injury and chronic wounds. In a systematic review, the molecular mechanisms triggered by HBO described within the last two decades were compiled. They cover a wide range of pathways, including transcription, cell-to-cell contacts, structure, adhesion and transmigration, vascular signaling and response to oxidative stress, apoptosis, autophagy and cell death, as well as inflammatory processes. By analyzing 71 predominantly experimental publications, we established an overview of the current concepts regarding the molecular mechanisms underlying the effects of HBO. We considered both the abovementioned pathways and their role in various applications and indications.
\end{abstract}

Keywords: hyperbaric oxygenation (HBO); reactive oxygen species (ROS); oxidative stress; tissue repair; molecular mechanism; transcription; vascular signaling; inflammation; cell structure; cell death

\section{Introduction}

\subsection{Basic Principles of Hyperbaric Oxygenation (HBO)}

The functional principle of HBO comprises the breathing of $100 \%$ oxygen under elevated ambient pressure higher than one atmosphere in a hyperbaric chamber. Based on the laws of Boyle-Mariotte, Dalton and Henry, the amount of oxygen in the plasma under hyperbaric conditions is many times higher than at sea level. Under these conditions, the amount of oxygen dissolved in the plasma shows a considerable rise according to the pressure applied, which results in a linear increase in arterial partial oxygen pressure $\left(\mathrm{paO}_{2}\right)$.

Under normobaric conditions, the $\mathrm{paO}_{2}$ ranges between 75 and $100 \mathrm{mmHg}$, whereas in therapeutic settings, when ambient pressures between 2.0 and 3.0 atmospheres are applied, a $\mathrm{paO}_{2}$ between 1200 and $2000 \mathrm{mmHg}$ is usually achieved. This considerable amount of dissolved oxygen even obviates the oxygenation via hemoglobin as long as the patient is exposed to HBO. However, beyond 3.0 atmospheres, HBO must not be delivered, because neurological side effects are inevitable when the dissolved oxygen fraction is further increased.

In the early years of its application, an ill-defined beneficial effect of "hyperoxygenation", which may persist up to several hours depending on the tissue, was presumed 
as the basic mechanism of $\mathrm{HBO}$. Obviously, hyperoxygenation also induces increased formation of reactive oxygen species (ROS), a fact that has been considered as an undesirable side-effect. It was the seemingly paradoxical beneficial impact of $\mathrm{HBO}$ on the ROS-triggered ischemia-reperfusion injury [1] that prompted meticulous research on the molecular mechanisms which form the basis of HBO treatment.

This HBO-induced high level of oxygen in the plasma and, in consequence, also in tissue has a number of pharmacological effects which are still used therapeutically for a variety of diseases. According to the level of evidence, the following concrete indications for $\mathrm{HBO}$ have been proven in clinical practice: decompression illness (DCI), arterial gas embolism (AGE), gas gangrene and necrotizing fasciitis, intracranial abscesses, problem wounds, burn injury, compartment syndrome, osteomyelitis, sequelae of radiation treatment (radiation cystitis, radiation proctitis, osteoradionecrosis) and carbon monoxide and cyanide poisoning $[2,3]$.

In this context, functional effects comprise vasoconstriction, edema reduction, antibacterial properties due to ROS, and the improvement of leukocytic phagocytosis, as well as the reoxygenation of mitochondrial enzymes. $\mathrm{HBO}$ also induces morphologic tissue alterations by promoting angiogenesis, formation of new vessels, collagen formation and neurogenesis. Furthermore, an influence on the interaction of different tissues can be seen by the inhibition of leucocyte adhesion to the vascular endothelium. Due to the inhibition of neuronal apoptosis, HBO also affects cellular signal transduction pathways. In addition, the mere increase in pressure causes ectopic gas bubbles to shrink according to the law of Boyle and Mariotte. Therefore, this effect is used for the treatment of AGE and DCI.

In infectious diseases, $\mathrm{HBO}$ is used successfully in the treatment of necrotizing soft tissue infections, chronic refractory osteomyelitis, opportunistic fungal infections and cerebral abscesses. The herein working HBO-related mechanisms include the direct bacteriostatic and bactericidal effects of HBO, the improvement of leukocytic phagocytosis, as well as a synergistic effect between oxygen and a number of antibiotics and antimycotics. The use of $\mathrm{HBO}$ in the treatment of chronic non-healing wounds can be attributed to the positive effects of $\mathrm{HBO}$ on wound healing by the induction of eovascularization and collagen formation. Due to inhibition of ischemia-reperfusion injury and lipid peroxidation, $\mathrm{HBO}$ has a positive impact on the preservation of post-ischemic tissues. Therefore, $\mathrm{HBO}$ is used in the treatment of acute myocardial and cerebral ischemia, in transplantation medicine, and also after traumatic soft tissue injuries.

In neurotraumatology, $\mathrm{HBO}$ is applied in the treatment of both acute and chronic traumatic brain injury (TBI) to prevent and to treat long-term sequelae. The main HBOinduced effect in this case is based on the limitation of secondary brain damage by inhibition of neuronal apoptosis. In the treatment of neuro-psychiatric sequelae after TBI, a marked advantage of $\mathrm{HBO}$ under a reduced pressure (low-pressure $\mathrm{HBO}$ ) compared to normobaric oxygen can be stated.

By means of the reoxygenation of mitochondrial enzymes of the respiratory chain, the increased oxygen concentration in the plasma as well as the inhibition free radicals cause lipid peroxidation, meaning that the use of $\mathrm{HBO}$ in acute-phase therapy and the treatment of long-term sequelae after several intoxications is possible.

In practice, HBO therapy is administered safely in a hyperbaric chamber at pressures up to 3 atmospheres according to schedules defined for the different indications mentioned above. There are different types of chambers available, whereas hospitals prefer large multi-place chambers that can treat approximately 6-10 people at a time and can easily accommodate patients lying on stretchers or in hospital beds. In chambers equipped for the treatment of critically ill patients, hyperbaric physicians and nurses accompany the patients during treatment. However, our division is equipped with the largest walk-in and drive-in hyperbaric chamber in central Europe, which enables the simultaneous treatment of up to five intensive care patients and which may even be used for intraoperative hyperbaric oxygenation. About 1200 compressions are performed every year, corresponding to more 
than 5000 single treatment sessions for in-hospital patients or for those in outpatient care, respectively (Figure 1).
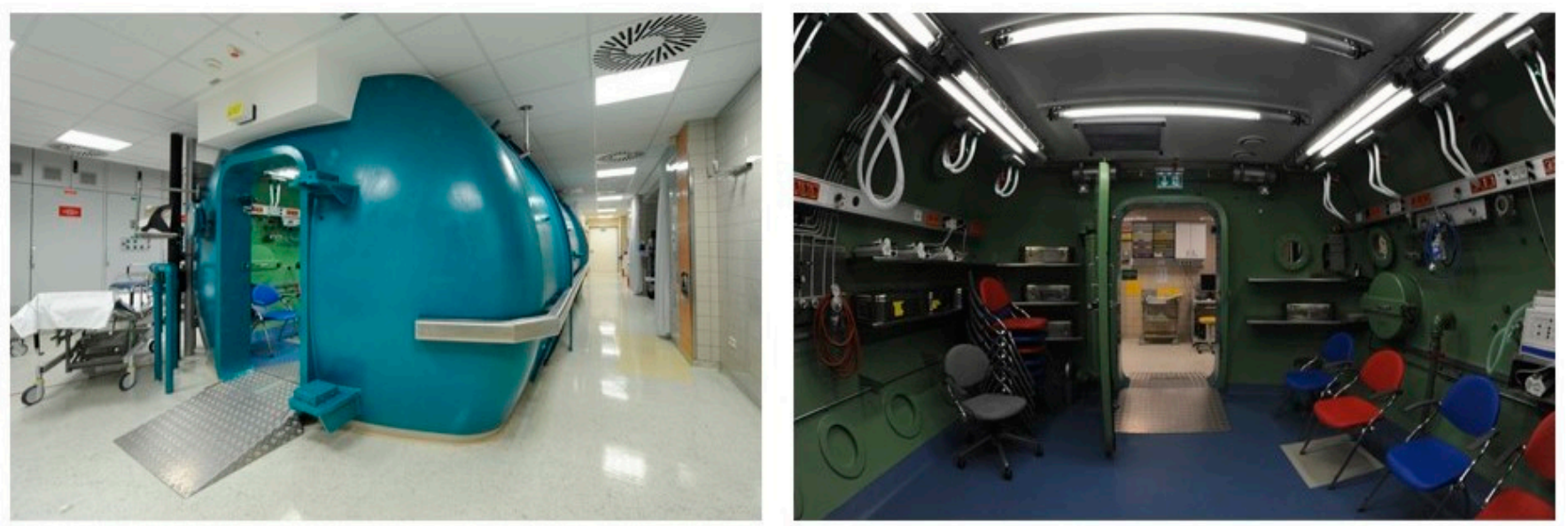

Figure 1. External and internal view of the hyperbaric chamber located at the Division of Thoracic and Hyperbaric Surgery, Department of Surgery, Medical University of Graz, Austria. Clearly visible are the white lines for the oxygen supply during the hyperbaric treatment in the internal space of the chamber. (Author's pictures).

\subsection{Methodology}

Today, a wide range of different molecular mechanisms influenced by $\mathrm{HBO}$ have been defined. They can be grossly grouped into five basic categories: transcription, vascular signaling and stress, vascular adhesion, cell-to-cell contacts and structure, inflammation, as well as apoptosis, autophagy and cell death. Depending on the various indications and underlying diseases, respectively, different arrays of mechanisms seem to be at work.

In this review based on the literature of the last twenty years, we tried to compile the most important, currently defined effects of $\mathrm{HBO}$ on the molecular level considering both the different categories and the indications.

Rather than trying to elucidate the complex metabolic pathways ensuing after the application of $\mathrm{HBO}$, we focused on a depiction of the findings.

In this context, we proceeded according to PRISMA guidelines. For the terms "hyperbaric" and "molecular mechanism", the OVID MEDLINE and PUBMED databases were searched, dating back to 2001. We included only publications for which full text was available. We excluded papers not providing sufficient information, redundant work, review articles, case reports and studies where $\mathrm{HBO}$ had been applied in combination with further specific medication. Papers dealing with HBO's effects on tumors or tumor cells were also not considered. Out of 8785 articles identified in OVID MEDLINE 56, and out of 180 in PUBMED, 22 publications were eligible. After the removal of 7 duplicates, a total of 71 papers were included. All but 3 studies were based on experimental settings. The majority of the experiments were performed in rats or mice by using standardized models. In 9 instances, the trials were based on tissue or cells which were derived from humans $(\mathrm{N}=6)$ or animals $(\mathrm{N}=3)$.

For better understanding, we grouped the mechanisms or substances identified in each study into the categories "transcription", "vascular signaling and stress", "(vascular) adhesion, cell-to-cell contacts and structure", "apoptosis, autophagy, cell death" and "inflammation". Since many items have an impact on more than one of these categories, double or triple allocations were made where it seemed appropriate. 


\section{Clinical Impact of HBO on the Different Molecular Mechanisms}

2.1. Classification in Respect of the Type of Research

2.1.1. Clinical Studies in Human Patients

Among these 71 publications, only four clinical studies dealing with the clinical impact of $\mathrm{HBO}$ in patients were available. In a prospective randomized trial involving 79 patients with a spinal cord injury, Sun and colleagues showed that the additional treatment with $\mathrm{HBO}$ regulated the inflammatory reaction, enabling neurological function recovery [4].

The remaining three clinical studies were conducted in the field of chronic wound healing. In a prospective randomized trial with 32 patients suffering from diabetic foot ulcers, supportive $\mathrm{HBO}$ was able to promote wound healing by stimulating angiogenesis, decreasing inflammation, and increasing the nitrite levels [5]. Similar results were obtained in another clinical study which proved the anti-inflammatory efficacy of HBO in patients with chronic diabetic wounds [6]. Moreover, in a prospective clinical trial involving 27 patients with diabetic food ulcers, adjunctive HBO resulted in accelerated wound healing by stimulating the vascular endothelial growth factor and the epidermal growth factor [7].

\subsubsection{In Vitro Studies Using Human Cell Lines}

To clarify the further beneficial impact of $\mathrm{HBO}$ on human cells, in vitro studies were conducted. In this context, only seven publications were identified.

In human coronary artery endothelial cells, $\mathrm{HBO}$ aided the enhancement of neovascularization by altering proangiogenic RNA [8].

With the help of $\mathrm{HBO}$ transiently, angiogenin gene expression was upregulated in human endothelial cells, which may lead to an enhancement of chronic wound healing [9]. Furthermore, HBO reduces the inflammation in wounds through reduced neutrophil recruitment, as proven in a model using human umbilical vein endothelial cells and neutrophils [10].

Similar results were obtained in a study using human microvascular endothelial cells. $\mathrm{HBO}$ promoted increased expression of immediate early and cytoprotective genes, leading to increased cell proliferation, enhanced endothelial tube formation and oxidative stress resistance [11]. Another beneficial effect was verified in human bone cells and human peripheral blood monocytes. Daily exposure to HBO led to a more pronounced antiosteoclastic effect as compared to hyperoxia or pressure alone, respectively. In this context, $\mathrm{HBO}$ prevented osteoclast formation and bone loss [12]. Similar findings were detected using mesenchymal stem cells (MSCs) harvested from the iliac bones of 12 patients. HBO treatment considerably accelerated bone formation by increasing osteogenic differentiation of those MSCs [13]. Furthermore, HBO had a protective impact on human lymphocytes by preventing DNA damage in the course of oxidant-mediated cell injury [14].

\subsubsection{In Vitro Studies Using Animal Cell Lines}

Only six in vitro studies using cell lines from rats $(\mathrm{N}=5)$ and mice $(\mathrm{N}=1)$ were identified. Two of them dealt with spinal cord injury. In this context, just a single exposure to HBO significantly increased intracellular levels of ROS and nitric oxide (NO), respectively [15]. In the second study, $\mathrm{HBO}$ was able to protect rat spinal neurons against oxidative injury and oxygen-glucose deprivation (OGD) [16]. Wound healing was accelerated by $\mathrm{HBO}$ in another two studies. One study using rat cells investigated the response of blood vessels with subsequent modulation of $\mathrm{NO}$ and vascular endothelial growth factor after $\mathrm{HBO}$ [17], whereas the second one showed in a mouse model that HBO stabilizes and activates HIF-1, resulting in increased cellular proliferation and the improvement of wound healing [18]. HBO-induced enhancement of neovascularization with subsequent regression of myocardial infarct size was verified in a rat model [19]. Finally, a stimulating effect of $\mathrm{HBO}$ on mandibular condylar chondrocytes in rats was observed. In this context, HBO protected chondrocytes against cytokine-related apoptosis and additionally promoted the expression of chondrocyte extracellular matrix [20]. 


\subsubsection{In Vivo Studies Using Animals}

The vast majority of animal studies $(\mathrm{N}=58)$ showing the beneficial impact of $\mathrm{HBO}$ in tissue repair and tissue regeneration were conducted using a standardized rat model.

The most investigated research areas of interest were wound healing or chronic wounds, ischemia-reperfusion injury, neuronal injury and pain, spinal cord injury and brain injury, intestinal barrier function, myocardial infarction, bone or cartilage, acute lung injury, lymphocytic function, atherosclerosis, and radiation-induced injury.

\subsection{Classification with Respect to the Molecular Mechanism or Function}

According to the underlying molecular mechanism and function, we grouped 44 findings into the category "transcription", 40 into "vascular signaling and stress", 28 into "(vascular) adhesion, cell-to-cell contacts and structure", 19 were assigned to "apoptosis, autophagy and cell death" and 36 to "inflammation". Regarding the complex mechanisms with their contacts at the molecular level, a number of publications covered more than only one classification, as shown in Figure 2.

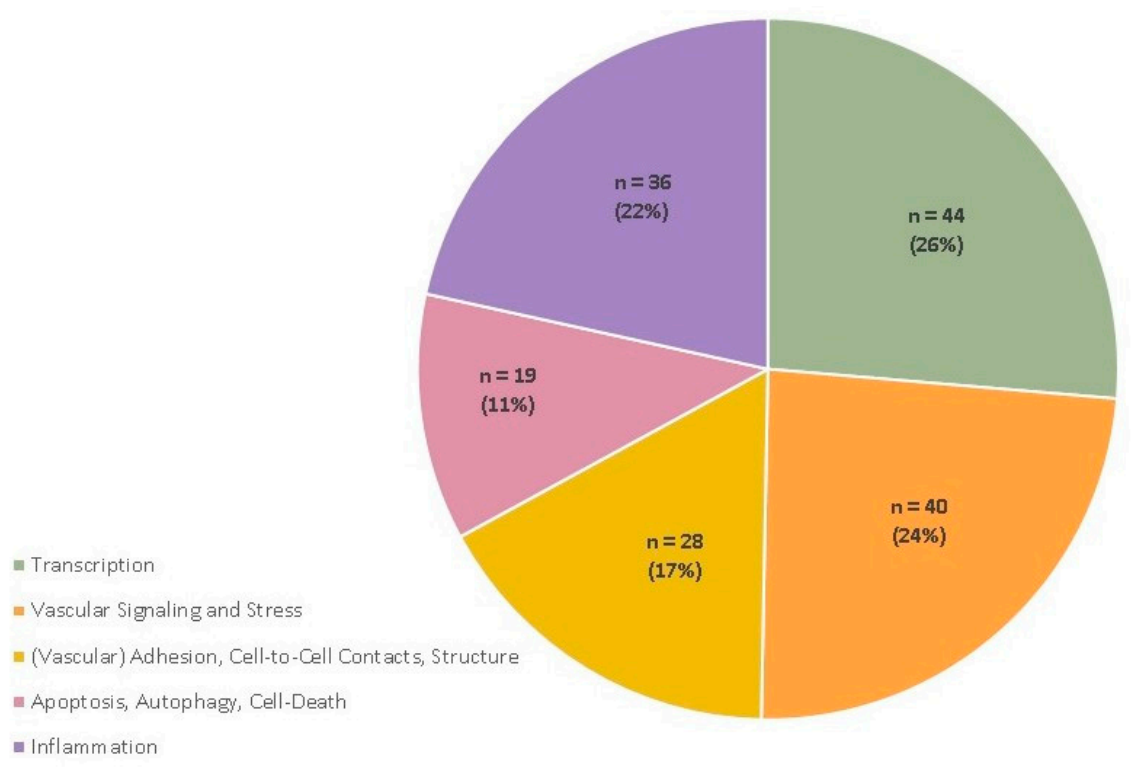

Figure 2. Number of papers per topic. Note that several papers provided input on multiple topics-therefore the absolute number is higher than number of references.

Ten items were assigned into two categories (cyclooxygenase 2 (COX2), epidermal growth factor (EFG), hypoxia-inducible factor 1-alpha (HIF1A), high mobility group protein 1 (HMGP1), mechanistic target of rapamycin (m-ToR), microtubule-associated protein 1A/1Blight chain 3 (LC3II), nuclear factor KappaB (NFKappaB), inducible nitric oxide synthase (i-NOS), tumor necrosis factor Alpha (TNF-Alpha) and vascular endothelial growth factor (VEGF)), and one was assigned into three categories (protein kinase B (Akt)).

Whenever $\mathrm{HBO}$ resulted in an increase or decrease in a function or a substance, the underlying mechanism notwithstanding, the result was indicated by an arrow. For eleven substances, both up- and downregulation was reported depending on the setting. The location and function of the respective substances, the effect of $\mathrm{HBO}$ on their expression or activity and the references are depicted in Table S1 in the Supplementary Materials section.

\subsubsection{Transcription}

The most investigated cytokine in this category is TNF-Alpha, which was studied by 11 authors who unanimously documented downregulation, despite a large variety of settings. Nine publications described HBO-induced downregulation of NFKappaB. For nuclear erythroid 2-related factor 2 (NRF2), all six authors reported upregulation. 
For HMGP1, downregulation was undisputed in three publications, and the same was true for p-53 gene reported by two authors. Krüppel-like factor 2 (KLF2) was found upregulated in two publications. The effect of $\mathrm{HBO}$ on all further 26 transcription factors in this category were described in one publication each.

There were also conflicting results. Protein kinase B (Akt) was found to be upregulated by four out of five investigators, whereas one reported downregulation. Likewise, four reports documented the action of HBO on VEGF, with three of them finding down- and one upregulation. Additionally, for $\mathrm{m}$-ToR, the results were divergent, with two papers reporting upregulation, whilst two others found downregulation of this protein.

In the main, transcription factors encoding proliferation, differentiation and protection from cell death were upregulated, whereas pro-inflammatory factors were diminished by $\mathrm{HBO}$.

\subsubsection{Vascular Signaling and Stress}

Nine publications documented an increase in superoxide dismutase (SOD) following $\mathrm{HBO}$, while nine authors found the same effect for heme-oxygenase 1 (HO-1). On the other hand, six papers unanimously described the downregulation of malondialdehyde (MDA), five found the same effect for matrix metalloproteinase 9 (MMP-9), four groups of investigators reported a reduction in myeloperoxidase (MPO) or i-NOS, respectively, and three reported the downregulation of COX-2 following HBO. Catalase (CAT) was found to be upregulated in four reports, and the same effect was documented in the publications for mitogen-activated protein kinase (MEK 1/2). Two papers each described the upregulation of nitric oxide (NO) (contradictory to the reduction in i-NOS) and the downregulation of C-Jun-N terminal kinases (JNK), respectively.

There was also a number of conflicting results following $\mathrm{HBO}$ application, as already outlined for the category "Transcription" concerning protein kinase B (Akt) and VEGF, which were also listed under "Vascular Signaling and Stress". In addition, HIF1A was investigated in six publications, four of which reported downregulation, whereas two found the factor to be upregulated. Glutathione (GSH) was found to be reduced in two and increased in a further two papers, ROS were documented as being increased by one and reduced by two groups of investigators, and glycogen synthase kinase-3 (GSK-3 beta) was reported as being reduced in one and increased in another publication. Hyperbaric oxygen was further found to trigger thioredoxin-mediated signaling cascades [21-23], which is a potential target for therapeutic intervention against human disorders such as tumorigenesis with natural molecules [24].

The remaining pharmacologically active agents had been investigated by one group of authors each.

To sum up, enzymes enhancing growth or differentiation, those with cytoprotective and antiapoptotic effects as well as mechanisms facilitating the reduction in oxidative stress were upregulated. Enzymes involved in pro-inflammatory cascades, or those enhancing the production of reactive oxygen species were downregulated.

\subsection{3. (Vascular) Adhesion, Cell-to-Cell Contacts, Structure}

HBO downregulated the intracellular adhesion molecule 1 (ICAM-1), as reported in four publications, three groups of investigators found microtubule-associated proteins 1A/1B light chain 3B (LC3II) to be downregulated, and the same effect was found for galectin 3 (GAL 3), for vascular cell adhesion molecule 1 (VCAM-1), and for glial fibrillary acidc protein (GFAP), as documented by two papers each. Upregulation, on the other hand, was reported for Beta-catenin 1 (CTNNB1), claudin-1 (CLDN1), and zonula occludens 1 (ZO 1), each being reported by two groups of investigators.

Thirteen further proteins were described by one publication each.

There were three conflicting results, one of them concerning protein kinase B (Akt), as described above, and another concerning LC3II, with two publications reporting upregula- 
tion and two others downregulation, as well as connexin (CX), which, depending on the time of observation, was found to be increased or decreased by one group of investigators.

In summary, functions involved in adhesion to endothelia and migration were downregulated, whilst cell-to-cell contacts, especially if based upon tight junctions, autophagy and cell motility showed upregulation.

\subsubsection{Apoptosis, Autophagy, Cell Death}

Four papers reported an upregulation of anti-apoptotic B cell lymphoma-2 (Bcl-2), while one group of authors found an increase in sirtuin-1 (SIRT-1). All other investigations showed the downregulation of the proteins in question, as documented by five reports for caspase 3 (CASP 3), cleaved caspase 3 (C3/pro C3) by three publications, Bcl-2-associated $X$ protein (Bax) in two reports and cryopyrin (NLRP-3) in a further two reports. Seven further proteins were described by one group of investigators each.

Divergent findings were reported for m-Tor, as already shown for the "Transcription" category, for LC3, as mentioned for "Vascular Adhesion, Cell-to-Cell Contacts and Structure", as well as for beclin 1 (BCN1), where two authors documented contradictory results.

Overall, pro-inflammatory mechanisms and such inducing or effectuating apoptosis or cell cycle arrest were downregulated, whereas anti-apoptotic processes and those linked to autophagy were stimulated. A comprehensive schematic diagram showing these mechanisms is demonstrated in Figure 3.

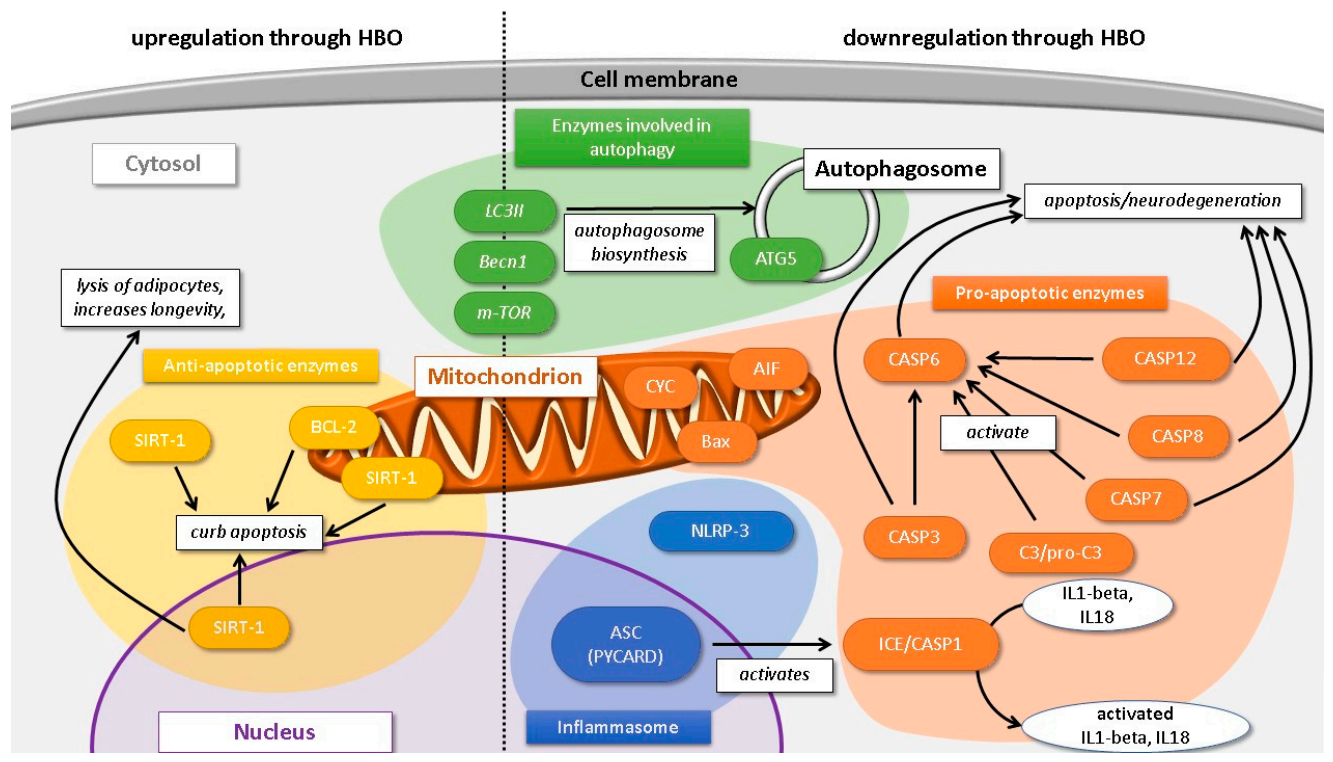

Figure 3. Current evidence suggests that hyperbaric oxygenation (HBO) exerts antiapoptotic effects via the downregulation of apoptotic enzymes: NLRP-3 interacts with components of damaged cells and, together with ASC, induces inflammation. Both form the inflammasome, engaging ICE/CASP1, which furthermore converts pro-inflammatory interleukins into an active form. $\mathrm{C} 3$ / pro-C3 activates CASP6, CASP6/7/8/12 engage CASP3, and all mediate and effect apoptosis. CYC, Bax and AIF reside in the mitochondria and are pro-apoptotic. Conversely, the antiapoptotic mitochondrial enzymes SIRT1 (also present in nucleus and cytosol) and BCL-2 are upregulated by HBO which in turn enhance cell viability as they curb apoptosis. $\mathrm{HBO}$ exerts variable effects on proteins in the cytosol, LC3II, Becn1 and m-TOR, which are involved in autophagy processes; however, there is evidence that ATG5 protein residing in autophagosome membrane is downregulated by HBO.

\subsubsection{Inflammation}

As in the categories "Transcription", "Vascular Signaling and Stress" and "Apoptosis, Autophagy Cell Death", TNF-Alpha, NF-KappaB, HMGP1, COX2, NLRP-3, and i-NOS were described as being downregulated. Ten publications confirmed the downregulation of 
interleukin 1beta (IL-1beta), four confirmed the decrease in i-NOS and three confirmed the downregulation of Toll-like receptor four (TLR-4). CxC motif chemokine 10 (CXCL10) was the only factor found to be enhanced by two authors. Ten cytokines were described by one respective publication. There were, however, conflicting reports concerning six modulating factors. They involved hypoxia inducible factor 1 Alpha (HIF1A) as described for "Vascular Signaling and Stress", transforming growth factor $B$ (TGF- $\beta$ ) and monocyte chemotactic protein 1 (MCP-1), for which two publications described up- or downregulation, respectively, and the types of interleukins. Out of four reports, two described interleukin 6 as being increased, while the other two found it decreased, while for interleukin 8 and interleukin 10, there were two conflicting reports each.

Composite, pro-inflammatory mechanisms were downregulated, making up for most of the publications. Only one item was reported to be increased after HBO.

\subsection{Molecular Mechanisms According to Underlying Conditions/Indications}

The majority of papers covered the underlying HBO-mechanisms in wound healing or chronic wounds $(\mathrm{N}=11)$, ischemia-reperfusion injury $(\mathrm{N}=11)$, neuronal injury and pain $(\mathrm{N}=7)$, spinal cord injury $(\mathrm{N}=14)$ and brain injury $(\mathrm{N}=14)$. A further 13 publications dealt with various issues such as intestinal barrier function $(\mathrm{N}=2)$, myocardial infarction $(\mathrm{N}=2)$, bone or cartilage $(\mathrm{N}=3)$, acute lung injury $(\mathrm{N}=2)$, lymphocytic function, atherosclerosis, radiation-induced injury and cerebral malaria (one each).

The molecular mechanisms and their respective changes after $\mathrm{HBO}$ application as described in each publication are depicted in Table S2 in the Supplementary Materials section.

\section{Discussion}

The positive effects of $\mathrm{HBO}$ on various conditions have been studied both in animal experiments and in clinical use since its introduction about 60 years ago. Based upon these analyses, $\mathrm{HBO}$ has reached a high level of evidence for many indications [2]. It was soon ascertained that HBO provides a reservoir of oxygen at the cellular level not only carried by the blood, but also by diffusion from the interstitial tissue, where it reaches a high concentration that may last for several hours [25]. Yet, as insight into the molecular mechanisms underlying physiological and pathological processes grew, the respective impact of $\mathrm{HBO}$ was also investigated.

These investigations entailed the awareness that the beneficial action of $\mathrm{HBO}$ not only relied on "better oxygenation", but was based on pharmacological effects $[3,26]$.

The main aim of this manuscript was to create a descriptive compilation of the most relevant results rather than trying to elucidate the respective underlying mechanisms. Exploring the functional aspects of each identified study in detail would have resulted in considerable complexity and extent, which would have significantly exceeded the scope of this manuscript.

The vast majority of the identified studies dealing with $\mathrm{HBO}$ in tissue regeneration are based on an experimental approach using either animals, animal or human tissue, or animal or human cells, as mentioned above. Although the beneficial impact of $\mathrm{HBO}$ for the different clinical indications has been shown during the last few years, clinical studies in this complex scientific field are still rare. However, there may be some reasons for this non-satisfying condition. First, HBO still remains a less widespread treatment in comparison to other well-established conservative or surgical treatment methods. Although this simple and safe therapy has been used for more than six decades, as mentioned above, only a few $\mathrm{HBO}$ experts and hyperbaric institutions worldwide know about the impact of this emerging and promising therapy. Second, the implementation of an adequate $\mathrm{HBO}$ center is associated with a considerable financial amount for the confronted hospital. Funding of the hyperbaric chamber, the required personnel and the further operating costs discourage most of the primarily interested institutions from making an investment. This is why HBO is still reserved to large hospitals, special centers of expertise and university hospitals, respectively. Third, this relatively small number of centers equipped 
with adequate technical requirements and high expertise in $\mathrm{HBO}$ represents a drawback for conducting meaningful clinical trials. Establishing large clinical multicenter trials is still hindered by both the small number of potentially participating institutions and the relatively small number of included patients due to the low incidence of clinical diseases (i.e., gas gangrene, air embolism). Fourth, the financial industrial backing for $\mathrm{HBO}$ is not given as compared to other clinical medical categories, such as oncology, transplantation surgery or the COVID-19 pandemic-related research. Therefore, these four reasons have to be taken into consideration when a considerable improvement in HBO-related research is initiated.

In order to establish a comprehensive overview about the related mechanisms, we grouped the parameters described in the various studies into five categories: "transcription", "vascular signaling and stress", "(vascular) adhesion, cell-to-cell contacts and structure", "apoptosis, autophagy, cell death" and "inflammation". Due to the fact that many substances are involved in more than one of these mechanisms, there had to be multiple assignments in some instances.

In the course of the preparation of this systematic review, it was obvious that the application of HBO in these various indications and pathophysiological models may result in different and conflicting molecular and biochemical findings. In this context, we sought to register extensively these different results and to point out the inconsistent data. However, despite these existing disparities in the outcome of $\mathrm{HBO}$, some common results were identified:

The impact of $\mathrm{HBO}$ on items depicted in the "transcription" category, a superordinate process, covers a wide range of points of action involved in cytoprotective, antiinflammatory pathways on the one hand $[9,15]$ and factors stimulating differentiation, collagen synthesis, epithelio-, neuro- and angiogenesis on the other $[8,11,27]$.

The findings regarding parameters linked to vascular signaling and stress confirmed that $\mathrm{HBO}$ counteracts hypoxia by improving oxygen delivery to areas with diminished blood flow. $\mathrm{HBO}$ reduces oxidative stress by means of the upregulation of scavengers, SOD [28-30], and interferes with neutrophil adhesion to endothelia while enhancing cellto-cell interaction at the level of tight- and gap junctions [31,32]. In case of impaired microcirculation, microvascular dynamics are improved by counteracting vasoconstriction, in part based on enhancement of the production of NO [17].

HBO thereby reduces or even reverses the pathological events resulting from hypoxia, or ischemia-reperfusion, especially endothelial function, rheology, increased vascular permeability, tissue edema, postischemia derangement of tissue metabolism, and eventually inflammation [1].

Increased oxygen free radical scavenging and reduced lipid oxidation may also be central mechanisms in reducing central nervous damage [28]. In this context, HBOpretreatment exerts a neuroprotective effect through the activation of protein kinase $\mathrm{B}(\mathrm{Akt})$ and the Toll-like receptor (TLR) 2/nuclear factor (NF)- $\mathrm{kB}$ signaling pathway, which entails the downregulation of pro-inflammatory cytokines [33].

The application of HBO modulated the expression of proteins involved in cell-to-cell adhesion and transmigration, e.g., ICAM-1, CTNNB1 [34,35], tight junctions [36,37], gap junctions [38], and components of the cytoskeleton and scaffolding such as actin alpha cardiac muscle (ACTC1), GFAP or vimentin [11,34,39].

HBO seems to directly prevent apoptosis via the LC3II and Bcl-2 pathways [37,40], additionally downregulating caspase-mediated cell apoptosis while enhancing autophagy [41]. In particular, neuronal apoptosis was reduced by downregulation of the $\mathrm{m}$-Tor pathway [42]. Signal transduction and gene expression in tissues sensitive to oxygen or hypoxia were modified [30,41]. Pro-inflammatory cytokines and chemokines, including COX2 [30], HIF1 [18,43], interferons 1, 6, 8 and 10 [9,37], as well as TNF-Alpha [44] and transforming growth factor beta (TGFBeta) [45], were downregulated by HBO, resulting in a decrease in leucocyte migration, edema and pain. 
Many investigations gave proof of the unidirectional action of $\mathrm{HBO}$ on pathways or substance. However, the intricate interactions of $\mathrm{HBO}$ at the molecular level become evident in the fact that $\mathrm{HBO}$ has also been shown to provoke opposing changes such as the up- or downregulation of one and the same marker. This applies to protein kinase $\mathrm{B}$ (Akt), VEGF, m-ToR, LC3II, CX, GSH, ROS, GSK-3 beta, BCN1, HIF1A, TGF- 1 , MCP-1 and to interleukin (IL-) 6, 8 and 10.

When taking a closer look at these seemingly inconsequential findings, it becomes evident that one reason for the disparities seems to lie in the respective baselines from which the interventions were started. $\mathrm{HBO}$ preconditioning before the initiation of an experimental intervention-i.e., in a basically healthy individual—changed the parameters in a different direction than that found under pathologic conditions. Likewise, IL-10 was upregulated following $\mathrm{HBO}$ treatment for chronic diabetic ulcers but downregulated after pretreatment for the healing of colonic anastomoses [5,44]. Similar observations were made when comparing the changes to mediators following $\mathrm{HBO}$ applied in chronic or acute disease. VEGF was found to be downregulated after HBO in a chronic, ischemic wound model, whereas it was upregulated in experimental spinal cord injury $[38,46]$. However, different etiologies of changes (e.g., diabetic vs. non-diabetic wound) also play a role, as evident in the different modifications of HIF1A in diabetic (upregulation) or non-diabetic chronic wounds (downregulation) [18,46].

It is conceivable that many more conflicting results could evolve if a larger number of single substances were investigated under different premises.

In conclusion, the studies suggest that there are well-founded molecular mechanisms, indicating that $\mathrm{HBO}$ may be helpful for ischemia-reperfusion injury, for chronic diabetic or non-diabetic wounds, neuronal and central nervous issues and inflammatory conditions, but work has to be done to ascertain the appropriate time to initiate HBO therapy and to establish criteria that determine whether patients will benefit [47].

The positive impact of $\mathrm{HBO}$ on many conditions notwithstanding, it should be kept in mind that the majority of data that provide the background to our understanding of the effects of hyperbaric oxygen on molecular level derive from experimental studies in animal models or cell cultures. It has yet to be established whether or how they translate into clinical use [1].

Authors should discuss the results and how they can be interpreted from the perspective of previous studies and of the working hypotheses. The findings and their implications should be discussed in the broadest context possible. Future research directions may also be highlighted.

Supplementary Materials: The following are available online at https:/ /www.mdpi.com/article/ $10.3390 /$ ijms222111754/s1, [48-85].

Author Contributions: F.M.S.-J. designed the first draft of the manuscript and was the advisor for this project. J.L. wrote the manuscript, including the tables, and performed the internal revisions and completed the manuscript submission process. C.S. wrote the manuscript and designed the scheme and performed the internal revisions. J.L. and C.S. contributed equally to this manuscript. L.-P.K. contributed to the internal revisions and provided scientific support. W.F.G. revised the first draft of the manuscript, contributed to the internal revisions and provided biochemical scientific support. All authors have read and agreed to the published version of the manuscript.

Funding: This research received no funding.

Institutional Review Board Statement: Not applicable.

Informed Consent Statement: Not applicable.

Data Availability Statement: Not applicable.

Acknowledgments: There are no acknowledgments.

Conflicts of Interest: The authors declare no conflict of interest. 


\section{References}

1. Francis, A.; Baynosa, R. Ischaemia-reperfusion injury and hyperbaric oxygen pathways: A review of cellular mechanisms. Diving Hyperb. Med. J. 2017, 47, 110-117. [CrossRef]

2. Mathieu, D.; Marroni, A.; Kot, J. Tenth European Consensus Conference on Hyperbaric Medicine: Recommendations for acepted and non-accepted clinical indications and practic of hyperbaric oxygten treatment. Diving Hyperb. Med. 2017, 47, 24-32. [CrossRef] [PubMed]

3. Smolle, C.; Lindenmann, J.; Smolle-Juettner, F.M. The History and Development of Hyperbaric Oxygenation (HBO) in Thermal Burn Injury. Medicina 2021, 57, 49. [CrossRef] [PubMed]

4. Sun, L.; Zhao, L.; Li, P.; Liu, X.; Liang, F.; Jiang, Y.; Kang, N.; Gao, C.; Yang, J. Effect of hyperbaric oxygen therapy on HMGB1/NFkappaB expression and prognosis of acute spinal cord injury: A randomized clinical trial. Neurosci. Lett. 2019, 692, 47-52. [CrossRef] [PubMed]

5. Dhamodharan, U.; Karan, A.; Sireesh, D.; Vaishnavi, A.; Somasundar, A.; Rajesh, K.; Ramkumar, K.M. Tissue-specific role of Nrf2 in the treatment of diabetic foot ulcers during hyperbaric oxygen therapy. Free Radic. Biol. Med. 2019, 138, 53-62. [CrossRef]

6. Baiula, M.; Greco, R.; Ferrazzano, L.; Caligiana, A.; Hoxha, K.; Bandini, D.; Longobardi, P.; Spampinato, S.; Tolomelli, A. Integrinmediated adhesive properties of neutrophils are reduced by hyperbaric oxygen therapy in patients with chronic non-healing wound. PLOS ONE 2020, 15, e0237746. [CrossRef]

7. Nasole, E.; Nicoletti, C.; Yang, Z.J.; Girelli, A.; Rubini, A.; Giuffreda, F.; Di Tano, A.; Camporesi, E.; Bosco, G. Effects of alpha lipoic acid and its R+ enantiomer supplemented to hyperbaric oxygen therapy on interleukin-6, TNF-alpha and EGF production in chronic leg wound healing. J. Enzym. Inhib. Med. Chem. 2014, 29, 297-302. [CrossRef]

8. Shyu, K.-G.; Wei Wang, B.-W.; Pan, C.-M.; Fang, W.-J.; Lin, C.-M. Hyperbaric oxygen boosts long noncoding RNA MALAT1 exosome secretion to suppress microRNA-92a expression in therapeutic angiogenesis. Int. J. Cardiol. 2019, 274, 271-278. [CrossRef]

9. Kendall, A.C.; Whatmore, J.L.; Harries, L.W.; Winyard, P.G.; Smerdon, G.R.; Eggleton, P. Changes in inflammatory gene expression induced by hyperbaric oxygen treatment in human endothelial cells under chronic wound conditions. Exp. Cell Res. 2012, 318, 207-216. [CrossRef]

10. Kendall, A.C.; Whatmore, J.L.; Winyard, P.G.; Smerdon, G.R.; Eggleton, P. Hyperbaric oxygen treatment reduces neutrophilendothelial adhesion in chronic wound conditions through S-nitrosation. Wound Repair Regen. 2013, 21, 860-868. [CrossRef] [PubMed]

11. Godman, C.A.; Chheda, K.P.; Hightower, L.E.; Perdrizet, G.; Shin, D.-G.; Giardina, C. Hyperbaric oxygen induces a cytoprotective and angiogenic response in human microvascular endothelial cells. Cell Stress Chaperones 2010, 15, 431-442. [CrossRef] [PubMed]

12. Al Hadi, H.; Smerdon, G.R.; Fox, S.W. Hyperbaric oxygen therapy suppresses osteoclast formation and bone resorption. J. Orthop. Res. 2013, 31, 1839-1844. [CrossRef] [PubMed]

13. Lin, S.S.; Ueng, S.W.; Niu, C.C.; Yuan, L.J.; Yang, C.Y.; Chen, W.J.; Lee, M.S.; Chen, J.K. Effects of hyperbaric oxygen on the osteogenic differentiation of mesenchymal stem cells. BMC Musculoskelet. Disord. 2014, 15, 56. [CrossRef]

14. Rothfuss, A.; Radermacher, P.; Speit, G. Involvement of heme oxygenase-1 (HO-1) in the adaptive protection of human lymphocytes after hyperbaric oxygen (HBO) treatment. Carcinogenesis 2001, 22, 1979-1985. [CrossRef]

15. Huang, G.; Diao, J.; Yi, H.; Xu, L.; Xu, J.; Xu, W. Signaling pathways involved in HSP32 induction by hyperbaric oxygen in rat spinal neurons. Redox Biol. 2016, 10, 108-118. [CrossRef]

16. Huang, G.; Xu, J.; Xu, L.; Wang, S.; Li, R.; Liu, K.; Zheng, J.; Cai, Z.; Zhang, K.; Luo, Y.; et al. Hyperbaric oxygen preconditioning induces tolerance against oxidative injury and oxygen-glucose deprivation by up-regulating heat shock protein 32 in rat spinal neurons. PLOS ONE 2014, 9, e85967.

17. Yuan, J.; Handy, R.D.; Moody, A.J.; Bryson, P. Response of blood vessels in vitro to hyperbaric oxygen (HBO): Modulation of VEGF and $\mathrm{NO}(\mathrm{x})$ release by external lactate or arginine. Biochim. Biophys. Acta 2009, 1787, 828-834. [CrossRef]

18. Sunkari, V.G.; Lind, F.; Botusan, I.R.; Kashif, A.; Liu, Z.-J.; Ylä-Herttuala, S.; Brismar, K.; Velazquez, O.; Catrina, S.-B. Hyperbaric oxygen therapy activates hypoxia-inducible factor 1 (HIF-1), which contributes to improved wound healing in diabetic mice. Wound Repair Regen. 2015, 23, 98-103. [CrossRef]

19. Shyu, K.-G.; Wang, B.-W.; Fang, W.-J.; Pan, C.-M.; Lin, C.-M. Hyperbaric oxygen-induced long non-coding RNA MALAT1 exosomes suppress MicroRNA-92a expression in a rat model of acute myocardial infarction. J. Cell. Mol. Med. 2020, 24, 12945-12954. [CrossRef]

20. Chen, H.; Wu, G.; Sun, Q.; Dong, Y.; Zhao, H. Hyperbaric oxygen protects mandibular condylar chondrocytes from interleukin$1 \beta$-induced apoptosis via the PI3K/AKT signaling pathway. Am. J. Transl. Res. 2016, 8, 5108-5117. [PubMed]

21. Zhen-Ni, G.; Xu, L.; Hu, Q.; Matei, N.; Yang, P.; Tong, L.-S.; He, Y.; Guo, Z.; Tang, J.; Yang, Y.; et al. Hyperbaric Oxygen Preconditioning Attenuates Hemorrhagic Transformation through Reactive Oxygen Species/Thioredoxin-Interacting Protein/Nod-Like Receptor Protein 3 Pathway in Hyperglycemic Middle Cerebral Artery Occlusion Rats. Crit. Care Med. 2016, 44, e403-e411.

22. Stroev, S.A.; Tjulkova, E.I.; Samoilov, M.O.; Pelto-Huikko, M.T. One- and three-time mild hypobaric hypoxia modifies expression of mitochondrial thioredoxin-2 in hippocampus of rat. Acta Neurobiol. Exp. 2011, 71, 244-255.

23. Peng, Y.; Feng, S.-F.; Wang, Q.; Wang, H.-N.; Hou, W.-G.; Xiong, L.; Luo, Z.-J.; Tan, Q.-R. Hyperbaric oxygen preconditioning ameliorates anxiety-like behavior and cognitive impairments via upregulation of thioredoxin reductases in stressed rats. Prog. Neuropsychopharmacol. Biol. Psychiatry 2010, 34, 1018-1025. [CrossRef] 
24. Zhang, J.; Duan, D.; Osama, A.; Fang, J. Natural Molecules Targeting Thioredoxin System and Their Therapeutic Potential. Antioxid. Redox Signal. 2021, 34, 1083-1107. [CrossRef] [PubMed]

25. Hentia, C.; Rizzato, A.; Camporesi, E.; Yang, Z.; Muntean, D.M.; Săndesc, D.; Bosco, G. An overview of protective strategies against ischemia/reperfusion injury: The role of hyperbaric oxygen preconditioning. Brain Behav. 2018, 8, e00959. [CrossRef]

26. Andel, H.; Kamolz, L.; Andel, D.; Brenner, L.; Frey, M.; Zimpfer, M. The use of oxygen as drug and its relevance for wound healing. In Handchirurgie, Mikrochirurgie, Plastische Chirurgie: Organ der Deutschsprachigen Arbeitsgemeinschaft für Handchirurgie: Organ der Deutschsprachigen Arbeitsgemeinschaft für Mikrochirurgie der Peripheren Nerven und Gefasse; Thieme: Stuttgart, Germany, 2007; Volume 39, pp. 328-332.

27. Chen, C.; Chen, W.; Nong, Z.; Nie, Y.; Chen, X.; Pan, X.; Guo, Y.; Yao, M.; Deng, W. Hyperbaric oxygen alleviated cognitive impairments in mice induced by repeated cerebral ischemia-reperfusion injury via inhibition of autophagy. Life Sci. 2020, 241, 117170. [CrossRef]

28. Sun, Y.; Liu, D.; Wang, Q.; Su, P.; Tang, Q. Hyperbaric oxygen treatment of spinal cord injury in rat model. BMC Neurol. 2017, 17, 128. [CrossRef]

29. Bai, C.; Li, T.; Chen, Y.; Xu, T.; Wang, X.; Yu, J.; Liu, X.; Sun, Q. Protective effects of hyperbaric oxygen preconditioning against LPS-induced acute lung injury in rats. Undersea Hyperb. Med. 2018, 45, 323-333.

30. Shams, Z.; Khalatbary, A.R.; Ahmadvand, H.; Zare, Z.; Kian, K. Neuroprotective effects of hyperbaric oxygen (HBO) therapy on neuronal death induced by sciatic nerve transection in rat. BMC Neurol. 2017, 17, 220. [CrossRef] [PubMed]

31. Li, H.-Z.; Chen, J.-F.; Liu, M.; Shen, J. Effect of hyperbaric oxygen on the permeability of the blood-brain barrier in rats with global cerebral ischemia/reperfusion injury. Biomed. Pharmacother. 2018, 108, 1725-1730. [CrossRef]

32. Liu, X.; Liang, F.; Zhang, J.; Li, Z.; Yang, J.; Kang, N. Hyperbaric Oxygen Treatment Improves Intestinal Barrier Function After Spinal Cord Injury in Rats. Front. Neurol. 2020, 11, 563281. [CrossRef] [PubMed]

33. Tan, J.; Zhang, F.; Liang, F.; Wang, Y.; Li, Z.; Yang, J.; Liu, X. Protective effects of hyperbaric oxygen treatment against spinal cord injury in rats via toll-like receptor 2/nuclear factor-kappaB signaling. Int. J. Clin. Exp. Pathol. 2014, 7, 1911-1919. [PubMed]

34. Lavrnja, I.; Parabucki, A.; Brkic, P.; Jovanovic, T.; Dacic, S.; Savic, D.; Pantic, I.; Stojiljkovic, M.; Pekovic, S. Repetitive hyperbaric oxygenation attenuates reactive astrogliosis and suppresses expression of inflammatory mediators in the rat model of brain injury. Mediat. Inflamm. 2015, 2015, 498405. [CrossRef]

35. He, H.; Li, X.; He, Y. Hyperbaric oxygen therapy attenuates neuronal apoptosis induced by traumatic brain injury via Akt/GSK3beta/beta-catenin pathway. Neuropsychiatr. Dis. Treat. 2019, 15, 369-374. [CrossRef]

36. Liu, X.; Liang, F.; Song, W.; Diao, X.; Zhu, W.; Yang, J. Effect of Nrf2 signaling pathway on the improvement of intestinal epithelial barrier dysfunction by hyperbaric oxygen treatment after spinal cord injury. Cell Stress Chaperon 2021, 26, 433-441. [CrossRef]

37. Chen, X.; Duan, X.-S.; Xu, L.-J.; Zhao, J.-J.; She, Z.-F.; Chen, W.-W.; Zheng, Z.-J.; Jiang, G.-D. Interleukin-10 mediates the neuroprotection of hyperbaric oxygen therapy against traumatic brain injury in mice. Neuroscience 2014, 266, 235-243. [CrossRef] [PubMed]

38. Liu, X.; Zhou, Y.; Wang, Z.; Yang, J.; Gao, C.; Su, Q. Effect of VEGF and CX43 on the promotion of neurological recovery by hyperbaric oxygen treatment in spinal cord-injured rats. Spine J. 2013, 14, 119-127. [CrossRef] [PubMed]

39. Zhou, Y.; Dong, Q.; Pan, Z.; Song, Y.; Su, P.; Niu, Y.; Sun, Y.; Liu, D. Hyperbaric Oxygen Improves Functional Recovery of the Injured Spinal Cord by Inhibiting Inflammation and Glial Scar Formation. Am. J. Phys. Med. Rehabil. 2019, 98, 914-920. [CrossRef]

40. Liu, Y.D.; Wang, Z.-B.; Han, G.; Jin, L.; Zhao, P. Hyperbaric oxygen relieves neuropathic pain through AKT/TSC2/mTOR pathway activity to induce autophagy. J. Pain. Res. 2019, 12, 443-451. [CrossRef]

41. Pan, J.Y.; Cai, R.-X.; Chen, Y.; Li, Y.; Lin, W.-W.; Wu, J.; Wang, X.-D. Analysis the effect of hyperbaric oxygen preconditioning on neuronal apoptosis, $\mathrm{Ca}+$ concentration and caspases expression after spinal cord injury in rats. Eur. Rev. Med. Pharmacol. Sci. 2018, 22, 3467-3473.

42. Chen, H.; Xu, G.; Wu, Y.; Wang, X.; Wang, F.; Zhang, Y. HBO-PC Promotes Locomotor Recovery by Reducing Apoptosis and Inflammation in SCI Rats: The Role of the mTOR Signaling Pathway. Cell. Mol. Neurobiol. 2020, 41, 1537-1547. [CrossRef] [PubMed]

43. Gu, G.J.; Li, Y.-P.; Peng, Z.-Y.; Xu, J.-J.; Kang, Z.-M.; Xu, W.-G.; Tao, H.-Y.; Ostrowski, R.P.; Zhang, J.-H.; Sun, X.-J. Mechanism of ischemic tolerance induced by hyperbaric oxygen preconditioning involves upregulation of hypoxia-inducible factor-1alpha and erythropoietin in rats. J. Appl. Physiol. 2008, 104, 1185-1191. [CrossRef] [PubMed]

44. Poyrazoglu, Y.; Topal, T.; Yuksel, R.; Bircan, F.S.; Simsek, K.; Gocgeldi, E.; Ersoz, N.; Korkmaz, A. Effects of Hyperbaric Oxygen and Preconditioning on Wound Healing in Colonic Anastomoses. J. Investig. Surg. 2015, 28, 188-195. [CrossRef]

45. Wee, H.-Y.; Lim, S.-W.; Chio, C.-C.; Niu, K.-C.; Wang, C.-C.; Kuo, J.-R. Hyperbaric oxygen effects on neuronal apoptosis associations in a traumatic brain injury rat model. J. Surg. Res. 2015, 197, 382-389. [CrossRef] [PubMed]

46. Zhang, Q.; Chang, Q.; Cox, R.A.; Gong, X.; Gould, L.J. Hyperbaric oxygen attenuates apoptosis and decreases inflammation in an ischemic wound model. J. Investig. Dermatol. 2008, 128, 2102-2112. [CrossRef]

47. Wang, C.; Schwaitzberg, S.; Berliner, E.; Zarin, D.A.; Lau, J. Hyperbaric Oxygen for Treating Wounds: A Systematic Review of the Literature. Arch. Surg. 2003, 138, 272-280. [CrossRef]

48. Yang, J.; Liu, X.; Zhou, Y.; Wang, G.; Gao, G.; Su, Q. Hyperbaric oxygen alleviates experimental (spinal cord) injury by downregulating HMGB1/NF-kappaB expression. Spine 2013, 38, E1641-E1648. [CrossRef] 
49. Wu, Z.-S.; Lo, J.-J.; Wu, S.-H.; Wang, C.-Z.; Chen, R.-F.; Lee, S.-S.; Chai, C.-Y.; Huang, S.-H. Early Hyperbaric Oxygen Treatment Attenuates Burn-Induced Neuroinflammation by Inhibiting the Galectin-3-Dependent Toll-Like Receptor-4 Pathway in a Rat Model. Int. J. Mol. Sci. 2018, 19, 2195. [CrossRef]

50. Kang, N.; Hai, Y.; Liang, F.; Gao, C.-J.; Liu, X.-H. Preconditioned hyperbaric oxygenation protects skin flap grafts in rats against ischemia/reperfusion injury. Mol. Med. Rep. 2014, 9, 2124-2130. [CrossRef]

51. Kang, N.; Hai, Y.; Yang, J.; Liang, F.; Gao, C.-J. Hyperbaric oxygen intervention reduces secondary spinal cord injury in rats via regulation of HMGB1/TLR4/NF-kB signaling pathway. Int. J. Clin. Exp. Pathol. 2015, 8, 1141-1153.

52. Ni, X.-X.; Nie, J.; Xie, Q.-Y.; Yu, R.-H.; Su, L.; Liu, Z.-F. Protective Effects of Hyperbaric Oxygen Therapy on Brain Injury by Regulating the Phosphorylation of Drp1 Through ROS/PKC Pathway in Heatstroke Rats. Cell. Mol. Neurobiol. 2020, 40, 1253-1269. [CrossRef]

53. Bastos, M.F.; Kayano, A.C.A.V.; Silva-Filho, J.-L.; Dos-Santos, J.C.; Judice, C.; Blanco, Y.C.; Shryock, N.; Sercundes, M.K.; Ortolan, L.S.; Francelin, C.; et al. Inhibition of hypoxia-associated response and kynurenine production in response to hyperbaric oxygen as mechanisms involved in protection against experimental cerebral malaria. FASEB J. 2018, 32, 4470-4481. [CrossRef]

54. Liu, Y.D.; Wang, Z.-B.; Han, G.; Zhao, P. Hyperbaric oxygen treatment attenuates neuropathic pain by elevating autophagy flux via inhibiting mTOR pathway. Am. J. Transl. Res. 2017, 9, 2629-2638.

55. Chen, C.; Chen, W.; Li, Y.; Dong, Y.; Teng, X.; Nong, Z.; Pan, Z.; Lv, L.; Gao, Y.; Wu, G. Hyperbaric oxygen protects against myocardial reperfusion injury via the inhibition of inflammation and the modulation of autophagy. Oncotarget 2017, 8, 111522111534. [CrossRef] [PubMed]

56. Hong-Qiang, H.; Mang-Qiao, S.; Fen, X.; Shan-Shan, L.; Hui-Juan, C.; Wu-Gang, H.; Wen-Jun, Y.; Zheng-Wu, P. Sirt1 mediates improvement of isoflurane-induced memory impairment following hyperbaric oxygen preconditioning in middle-aged mice. Physiol. Behav. 2018, 195, 1-8. [CrossRef]

57. Zhang, Y.; Lv, Y.; Liu, Y.-J.; Yang, C.; Hu, H.-J.; Meng, X.-E.; Li, M.-X.; Pan, S.-Y. Hyperbaric oxygen therapy in rats attenuates ischemia-reperfusion testicular injury through blockade of oxidative stress, suppression of inflammation, and reduction of nitric oxide formation. Urology 2013, 82, 489.e9-489.e15. [CrossRef] [PubMed]

58. Wang, M.; Cheng, L.; Chen, Z.-L.; Mungur, R.; Xu, S.-H.; Wu, J.; Liu, X.-L.; Wan, S. Hyperbaric oxygen preconditioning attenuates brain injury after intracerebral hemorrhage by regulating microglia polarization in rats. CNS Neurosci. Ther. 2019, 25, 1126-1133. [CrossRef]

59. Yang, Z.J.; Bosco, G.; Montante, A.; Ou, X.I.; Camporesi, E.M. Hyperbaric O2 reduces intestinal ischemia-reperfusion-induced TNF-alpha production and lung neutrophil sequestration. Eur. J. Appl. Physiol. 2001, 85, 96-103. [CrossRef] [PubMed]

60. Ding, Y.; Yao, P.; Hong, T.; Li, H.; Zhu, Y.; Han, Z.; Zhou, G. The analgesic effect of early hyperbaric oxygen treatment in chronic constriction injury rats and its influence on nNOS and iNOS expression and inflammatory factor production. Mol. Pain 2018, 14, 1744806918765837. [CrossRef]

61. Zhao, B.; Pan, Y.; Xu, H.; Song, X. Hyperbaric oxygen attenuates neuropathic pain and reverses inflammatory signaling likely via the Kindlin-1/Wnt-10a signaling pathway in the chronic pain injury model in rats. J. Headache Pain 2017, 18, 1-8. [CrossRef]

62. Lim, S.-W.; Sung, K.-C.; Shiue, Y.-L.; Wang, C.-C.; Chio, C.-C.; Kuo, J.-R. Hyperbaric Oxygen Effects on Depression-Like Behavior and Neuroinflammation in Traumatic Brain Injury Rats. World Neurosurg. 2017, 100, 128-137. [CrossRef]

63. Liu, H.; Yang, M.; Pan, L.; Liu, P.; Ma, L. Hyperbaric Oxygen Intervention Modulates Early Brain Injury after Experimental Subarachnoid Hemorrhage in Rats: Possible Involvement of TLR4/NF-x03BA.; B-Mediated Signaling Pathway. Cell. Physiol. Biochem. Int. J. Exp. Cell. Physiol. Biochem. Pharmacol. 2016, 38, 2323-2336. [CrossRef]

64. Yang, Y.; Wei, H.; Zhou, X.; Zhang, F.; Wang, C. Hyperbaric oxygen promotes neural stem cell proliferation by activating vascular endothelial growth factor/extracellular signal-regulated kinase signaling after traumatic brain injury. Neuroreport 2017, 28 , 1232-1238. [CrossRef] [PubMed]

65. Oliveira, M.S.; Tanaka, L.Y.; Antonio, E.L.; Brandizzi, L.I.; Serra, A.J.; Dos Santos, L.; Krieger, J.E.; Laurindo, F.R.M.; Tucci, P.J.F. Hyperbaric oxygenation improves redox control and reduces mortality in the acute phase of myocardial infarction in a rat model. Mol. Med. Rep. 2020, 21, 1431-1438. [CrossRef]

66. Kudchodkar, B.J.; Pierce, A.; Dory, L. Chronic hyperbaric oxygen treatment elicits an anti-oxidant response and attenuates atherosclerosis in apoE knockout mice. Atherosclerosis 2007, 193, 28-35. [CrossRef] [PubMed]

67. Nguyen, T.T.; Jones, J.I.; Wolter, W.R.; Pérez, R.L.; Schroeder, V.A.; Champion, M.M.; Hesek, D.; Lee, M.; Suckow, M.A.; Mobashery, $\mathrm{S}$. Hyperbaric oxygen therapy accelerates wound healing in diabetic mice by decreasing active matrix metalloproteinase-9. Wound Repair Regen. 2020, 28, 194-201. [CrossRef] [PubMed]

68. Huang, Z.-X.; Kang, Z.-M.; Gu, G.-J.; Peng, G.-N.; Yun, L.; Tao, H.-Y.; Xu, W.-G.; Sun, X.-J.; Zhang, J.H. Therapeutic effects of hyperbaric oxygen in a rat model of endothelin-1-induced focal cerebral ischemia. Brain Res. 2007, 1153, 204-213. [CrossRef]

69. Nesovic Ostojic, J.; Ivanov, M.; Mihailovic-Stanojevic, N.; Karanovic, D.; Kovacevic, S.; Brkic, P.; Zivotic, M.; Vajic, U.J.; Jovovic, D.; Jeremic, R.; et al. Hyperbaric Oxygen Preconditioning Upregulates Heme OxyGenase-1 and Anti-Apoptotic Bcl-2 Protein Expression in Spontaneously Hypertensive Rats with Induced Postischemic Acute Kidney Injury. Int. J. Mol. Sci. 2021, $22,1382$. [CrossRef]

70. Huang, T.-Y.; Tsai, P.-S.; Wang, T.-Y.; Huang, C.-L.; Huang, C.-J. Hyperbaric oxygen attenuation of lipopolysaccharide-induced acute lung injury involves heme oxygenase-1. Acta Anaesthesiol. Scand. 2005, 49, 1293-1301. [CrossRef] 
71. Gajendrareddy, P.K.; Sen, C.K.; Horan, M.P.; Marucha, P.T. Hyperbaric oxygen therapy ameliorates stress-impaired dermal wound healing. Brain Behav. Immun. 2005, 19, 217-222. [CrossRef]

72. Zhao, H.; Zhang, Q.; Xue, Y.; Chen, X.; Haun, R.S. Effects of hyperbaric oxygen on the expression of claudins after cerebral ischemia-reperfusion in rats. Exp. Brain Res. 2011, 212, 109-117. [CrossRef]

73. Veltkamp, R.; Bieber, K.; Wagner, S.; Beynon, C.; Siebing, D.A.; Veltkamp, C.; Schwaninger, M.; Marti, H.H. Hyperbaric oxygen reduces basal lamina degradation after transient focal cerebral ischemia in rats. Brain Res. 2006, 1076, 231-237. [CrossRef] [PubMed]

74. Wang, Y.; Li, C.; Gao, C.; Li, Z.; Yang, J.; Liu, X.; Liang, F. Effects of hyperbaric oxygen therapy on RAGE and MCP-1 expression in rats with spinal cord injury. Mol. Med. Rep. 2016, 14, 5619-5625. [CrossRef]

75. Zelinski, L.M.; Ohgami, Y.; Chung, E.; Shirachi, D.Y.; Quock, R.M. A prolonged nitric oxide-dependent, opioid-mediated antinociceptive effect of hyperbaric oxygen in mice. J. Pain 2009, 10, 167-172. [CrossRef] [PubMed]

76. Fu, H.; Li, F.; Thomas, S.; Yang, Z. Hyperbaric oxygenation alleviates chronic constriction injury (CCI)-induced neuropathic pain and inhibits GABAergic neuron apoptosis in the spinal cord. Scand. J. Pain 2017, 17, 330-338. [CrossRef]

77. Zhao, F.; Wang, X.; Liang, T.; Bao, D.; Wang, Y.; Du, Y.; Li, H.; Du, J.; Chen, A.; Fu, Z.; et al. Effect of Hyperbaric Oxygen on Tissue Damage and Expression of Adhesion Molecules and C3 in a Rat Model of Renal Ischemia-Reperfusion Injury After Kidney Transplantation. Ann. Transplant. 2020, 25, e919385. [CrossRef]

78. Sun, Y.; Liu, D.; Su, P.; Lin, F.; Tang, Q. Changes in autophagy in rats after spinal cord injury and the effect of hyperbaric oxygen on autophagy. Neurosci. Lett. 2016, 618, 139-145. [CrossRef]

79. Bao, D.-S.; Wu, Y.-K.; Fu, S.-J.; Wang, G.-Y.; Yang, S.-J.; Liang, G.-B.; Xie, Z.-H.; Rong, S. Hyperbaric Oxygenation Protects Against Ischemia-Reperfusion Injury in Transplanted Rat Kidneys by Triggering Autophagy and Inhibiting Inflammatory Response. Ann. Transplant. 2017, 22, 75-82. [CrossRef]

80. Liu, X.; Wang, J.; Li, G.; Lv, H. Effect of combined chondroitinase ABC and hyperbaric oxygen therapy in a rat model of spinal cord injury. Mol. Med. Rep. 2018, 18, 25-30. [CrossRef]

81. Liang, F.; Li, C.; Gao, C.; Li, Z.; Yang, J.; Liu, X.; Wang, Y. Effects of hyperbaric oxygen therapy on NACHT domain-leucine-richrepeat- and pyrin domain-containing protein 3 inflammasome expression in rats following spinal cord injury. Mol. Med. Rep. 2015, 11, 4650-4656. [CrossRef] [PubMed]

82. Liu, X.H.; Yan, H.; Xu, M.; Zhao, Y.-L.; Li, L.-M.; Zhou, X.-H.; Wang, M.-X.; Ma, L. Hyperbaric oxygenation reduces long-term brain injury and ameliorates behavioral function by suppression of apoptosis in a rat model of neonatal hypoxia-ischemia. Neurochem. Int. 2013, 62, 922-930. [CrossRef] [PubMed]

83. Qian, H.; Li, Q.; Shi, W. Hyperbaric oxygen alleviates the activation of NLRP-3-inflammasomes in traumatic brain injury. Mol. Med. Rep. 2017, 16, 3922-3928. [CrossRef] [PubMed]

84. Zhou, Y.; Su, P.; Pan, Z.; Liu, D.; Niu, Y.; Zhu, W.; Yao, P.; Song, Y.; Sun, Y. Combination Therapy with Hyperbaric Oxygen and Erythropoietin Inhibits Neuronal Apoptosis and Improves Recovery in Rats with Spinal Cord Injury. Phys. Ther. 2019, 99, 1679-1689. [CrossRef]

85. Spiegelberg, L.; Swagemakers, S.M.A.; Van Ijcken, W.F.J.; Oole, E.; Wolvius, E.B.; Essers, J.; Braks, J.A.M. Gene expression analysis reveals inhibition of radiation-induced TGF $\beta$-signaling by hyperbaric oxygen therapy in mouse salivary glands. Mol. Med. 2014, 20, 257-269. [CrossRef] [PubMed] 